of biological uses for solar energy ranging from waste treatment to fish farming. He envisages Arab countries such as Kuwait, whose national development plan is very conscious of, and aims for, a balance between ecosystems, providing the vision and financial resources for a regional development effort based on an international input of scientific manpower. This would help to make each side in the Middle East conflict dependent on the other for its future.

As none of IFIAS' projects has yet been completed it is too early to talk about their final results. Already, however, there are signs that IFIAS' work is not going unnoticed. The Brussels headquarters of the Common Market has asked IFIAS for information about the energy analysis programme, and has reserved $\$ 100,000$ for a joint IFIAS/ Common Market project on energy. The Market is particularly interested in adopting IFIAS' methodology for working out alternative levels of energy consumption, with a view to using the technique in drawing up a European energy policy. The World Health
Organisation is also very interested in an IFIAS project; this time the one on enzyme engineering. WHO's attention is concentrated on that part of the project dealing with the new method IFIAS has developed for diagnosing tropical diseases. The method was tested in East Africa last February and looks promising.

The first evaluation of IFIAS will no doubt be the one planned by the organisation itself, to be conducted in 1977-five years after its inception. This idea is good in principle, but should not be expected to produce any rational calculation of its achievements. One of the problems involved is the lack of any concrete output or of any yardstick to measure it. Barring administrative incompetence, each team of institutes will obviously be able to produce lengthy documents supporting the results of its particular project. By then they will also perhaps be able to point to even more examples of their work being referred to by the decision makers.

The continuation of IFIAS will depend not on the results of 'evalua- tions' of its work but on the enthusiasm of its members. And nothing could be calculated to sustain that enthusiasm more than the sort of successes the energy analysis and enzyme engineering projects have already enjoyed. Convincing decision makers of the need for action may be harder in the project on climate change. The invisibility of the problem makes it an unlikely target for that public concern which, in countries where politicians depend on the people for their positions, can be an effective complement to IFIAS' high-level approaches in making the decision makers act. On the other hand, the problems dealt with in the project on human settlements are symbolised by the ugliness, dirtiness and congestion of modern cities. If handled properly, the project could have an impact on public policy. Unfortunately, the impact will be greatest if IFIAS keeps its activities separate from the UN conference towards which they are aimed; for incisive and intelligent proposals have a way of emerging from the politicallysensitive and grindingly slow UN machine in a very emaciated form.
Somenow or other, they had cajoled the money and effort to try their strange and fabulously expensive experiment. Many people said that the funds should be spent on something more useful, or not spent at all. But there was a great public curiosity in the idea; perhaps Orson Welles had helped as much as anyone with his radio broadcast of invaders from Mars in 1938 that caused a nationwide panic. Is there life on Mars? We were now ready to settle for a few anaerobic bacteria rather than green monsters with fusiform antennæ.

The Viking biology team had been called together by the team leader, Harold Klein, for the last time before the launch on August 11, 1975.

One year ago, our hope that even one of the three experiments would be ready by launch-time was a slender one. The constraints were severe; everything that is sent to Mars must be sterile. There is no use carrying bacterial spores from Earth to Mars to detect their presence later. It cost about a million dollars to sterilise the parachute, principally because no-one had ever sterilised a parachute. "Hardy bugs" kept showing up, including one whose spores lived for 6 days at $125^{\circ} \mathrm{C}$. The launch date had to be just right for slinging a shot through the heavens to intercept a planet in conjunction. Worst of all, the instruments were unprecedented in design, infinite in complexity, and strictly limited in size and weight. In engineers' terms, they cost a million dollars per pound; a compacted 20 -kilogram mass of electronic and chemical gadgetry whose price made crown jewels look like dime-store baubles. One of the experiments is called "labeled release". It will incubate a pinch of Martian soil, moistened with water containing radioactively tagged nutrients (formate, glycine, DL alanine, DL lactate and glycolicic acid)

\section{Viking gets ready} from Thomas $H$. Jukes

for two weeks at $6^{\circ}-14^{\circ} \mathrm{C}$, and any emitted gas will be monitored for metabolically-produced radioactivity.

The second is "pyrolytic release", based on the idea that photosynthetic fixation of carbon dioxide, and possibly carbon monoxide, should take place biologically under Martian conditions. The surface sample will be exposed to "artificial sunlight" from a xenon lamp for several days in an atmosphere containing ${ }^{14} \mathrm{CO}_{2}$ and a little ${ }^{14} \mathrm{CO}$. The soil will then be heated to $600{ }^{\circ} \mathrm{C}$ to destroy organic compounds resulting from photosynthesis and the emitted gases will be measured for radioactivity. The experiment is designed also to detect dark fixation of ${ }^{14} \mathrm{CO}_{2}$ and ${ }^{14} \mathrm{CO}$. This experiment is specifically oriented towards Martian organisms that may differ from terrestrial ones in being intolerant of water or "terrestrial nutrients". The third experiment is named "gas exchange" but is often called "the
chicken soup experiment" because it frankly seeks to woo Martian bugs with a rich, non-radioactive meal containing amino acids, vitamins and cofactors, salts and other nutrients, from kitchens on the Earth. The soil sample is moistened with the culture medium, and the atmosphere in the chamber, mostly helium, is periodically analysed by gas chromatography to see if gases such as methane and $\mathrm{CO}_{2}$ are emitted.

At the meeting on June 17, the engineers from Thompson-Ramo-Wooldridge and Martin-Marietta appropriately handed us a glossary of 80 acronyms to help us follow their talks. The mood was one of relief, and guarded optimism. All three of the experimental instruments, miraculously, had come into working order at the last minute. The Viking Biology package, in duplicate, had been loaded into two spacecraft at the Kennedy Space Center in Florida. All that now remains is that the instruments should survive the launches on August 11 and 21 , the eleven-month, 450-million-mile journey, and the "soft" landings through the thin (5 millibars) $\mathrm{CO}_{2}$ atmosphere of Mars in July 1976.

After that, perhaps, the faintly-whispered signals will tell us what is happening; not only in the biology package but in the colour cameras, the water detector, the infra-red thermal mapper, the gas-chromatograph-mass - spectrometer, the X-ray fluorescence spectrometer, the seismometer and the weather station. But a main worry is: if the signals next year say that life may be present, will people believe the message? 